\title{
New technique of local ischemic preconditioning induction without repetitive aortic cross-clamping in cardiac surgery
}

Dmitry I Kurapeev ${ }^{1}$, Viktor O Kabanov², Vadim K Grebennik², Tatyana A Sheshurina², Vladimir V Dorofeykov², Michael M Galagudza ${ }^{1,3^{*}}$ and Eugene V Shlyakhto ${ }^{2}$

\begin{abstract}
Background: Several studies have demonstrated that local ischemic preconditioning can reduce myocardial ischemia-reperfusion injury in cardiac surgery patients; however, preconditioning has not become a standard cardioprotective intervention, primarily because of the increased risk of atheroembolism during repetitive aortic cross-clamping. In the present study, we aimed to describe and validate a novel technique of preconditioning induction.
\end{abstract}

Methods: Patients undergoing coronary artery bypass grafting (12 women and 78 men; mean age, $56 \pm 11$ years) were randomized into 3 groups: (1) Controls $(n=30)$, (2) Perfusion $(n=30)$, and (3) Preconditioning $(n=30)$. All patients were operated under cardiopulmonary bypass using normothermic blood cardioplegia. Preconditioning was induced by subjecting the hemodynamically unloaded heart to 2 cycles of 3 min of ischemia and 3 min of reperfusion with normokalemic blood prior to cardioplegia. In the Perfusion group, the heart perfusion remained unaffected for $12 \mathrm{~min}$. Troponin I (Thl) levels were analyzed before surgery, and 12, 24, 48 h, and 7 days after surgery. The secondary endpoints included the cardiac index, plasma natriuretic peptide level, and postoperative use of inotropes.

Results: Preconditioning resulted in a significant reduction in the Tnl level on the 7th postoperative day only $(0.10 \pm 0.05$ and $0.33 \pm 0.88 \mathrm{ng} / \mathrm{ml}$ in Preconditioning and Perfusion groups, respectively, $P<0.05)$. In addition, cardiac index was significantly higher in the Preconditioning group than in the Control and Perfusion groups just after weaning from cardiopulmonary bypass. The number of patients requiring inotropic support with $\geq 2$ agents after surgery was significantly lower in the Preconditioning and Perfusion group than in the Control group $(P<0.05)$. No complications of the procedure were recorded in the Preconditioning group.

Conclusions: The preconditioning procedure described can be performed safely in cardiac surgery patients. The application of this technique of preconditioning was associated with certain benefits, including improved left ventricular function after weaning from cardiopulmonary bypass and a reduced need for inotropic support. However, the infarct-limiting effect of preconditioning in the early postoperative period was not evident. The procedure does not involve repetitive aortic cross-clamping, thus avoiding possible embolic complications.

Keywords: Local ischemic Preconditioning, Myocardial ischemia-reperfusion, Cardioplegia, Cardiopulmonary bypass, Troponin I, Cardiac index

\footnotetext{
* Correspondence: galagoudza@mail.ru

${ }^{1}$ Institute of Experimental Medicine, Federal Almazov Medical Research

Centre, Saint Petersburg, Russian Federation

${ }^{3}$ Department of Pathophysiology, First I.P. Pavlov Federal Medical University

of St. Petersburg, Saint Petersburg, Russian Federation

Full list of author information is available at the end of the article
} 


\section{Background}

Although the number of open heart surgeries performed each year has declined in the past decade, the proportion of very elderly patients with multiple comorbidities and/ or multivessel coronary artery disease (CAD) undergoing major heart surgery is continuously increasing [1]. The peri- and postoperative mortality and morbidity has been reported to be increased in this patient population $[2,3]$, which may be attributed-at least in part-to suboptimal myocardial protection due to a longer duration of aortic cross-clamping in advanced CAD [4], as well as the enhanced susceptibility of the aged and diabetic myocardium to ischemia-reperfusion injury (IRI) $[5,6]$. Therefore, the development and application of new cardioprotective approaches in cardiac surgery remains important.

Increased myocardial tolerance to IRI after a single episode or several brief episodes of ischemia-reperfusion is referred to as local ischemic preconditioning (IP) [7]. A large body of experimental evidence suggests that IP represents one of the most effective endogenous cardioprotective interventions developed thus far $[8,9]$. The predictability of ischemia onset and direct access to the heart are 2 major prerequisites for the successful clinical use of IP, both of which are fulfilled during open heart operations with cardiopulmonary bypass (CPB). At present, the cardioprotective effectiveness of IP in cardiac surgery patients has been demonstrated in several small clinical trials. In particular, IP has been shown to reduce the postoperative levels of cardiac troponins [10] and to improve left and right ventricular contractile function $[11,12]$. In addition, the beneficial effects of IP on certain clinical endpoints, such as the incidence of ventricular arrythmias [13], inotrope requirements [14], and intensive care unit (ICU) stay [15], have been clearly demonstrated. In all these studies, IP was induced after the initiation of CPB by 1 or 2 brief (1-5 min) cycles of aortic clamping followed by reperfusion prior to cardioplegic arrest. Although this protocol of IP induction seems to be safe in pediatric patients with congenital heart defects [16], repetitive aortic cross-clamping might be associated with an increased risk of atheroembolism in adult patients with diffuse atherosclerosis undergoing coronary artery bypass graft (CABG) surgery [17]. Thus, the development of alternative techniques of IP induction without repetitive (de)clamping of the ascending aorta is important.

In the present study, we describe a new technique of IP induction that does not require repeated aortic cross-clamping in patients undergoing cardiac surgery. In addition, we assessed the effects of the modified IP technique on serum cardiac troponin I (cTnI) and brain natriuretic peptide (BNP) levels, cardiac index (CI), left ventricular function, and clinical parameters in CABG patients.

\section{Methods}

This single-center, double-blinded, randomized controlled study conforms to the principles outlined in the Declaration of Helsinki and UCL Good Clinical Practice Guidelines. The study design was approved by the ethics committees at Federal Almazov Medical Research Centre, St Petersburg, Russian Federation. Written informed consent was obtained from each patient before the operation.

\section{Inclusion/exclusion criteria}

From March 2010 to October 2013, 90 patients (12 women and 78 men; mean age, $56 \pm 11$ [standard deviation] years) with 3-vessel CAD admitted for elective CABG surgery were enrolled in the prospective study. Patients with severe non-coronary cardiac disease, left ventricular ejection fraction $<50 \%$, unstable angina, or history of myocardial infarction within 3 months prior to surgery were excluded. Patients with diabetes mellitus and those receiving inotropic agents prior to $\mathrm{CPB}$ were also excluded.

\section{Anesthesia and surgical technique}

Premedication consisted of oral benzodiazepines and intramuscular morphine $(0.15 \mathrm{mg} / \mathrm{kg})$ given $1.5 \mathrm{~h}$ preoperatively. Before anesthesia, the right radial artery was cannulated and a Swan-Ganz pulmonary artery catheter was introduced through the right jugular vein. The patients were anesthetized by intravenous infusion of fentanyl and propofol. Pipecuronium bromide $(0.15 \mathrm{mg} / \mathrm{kg})$ was used for muscle relaxation. The activated clotting time was maintained at $>450 \mathrm{~s}$. CPB was established with a single 2-stage venous cannula and ascending aortic cannula. During $\mathrm{CPB}$, the core body temperature was maintained at $36.0^{\circ} \mathrm{C} \pm 0.5^{\circ} \mathrm{C}$. The pump volume flow rate was $2.4-$ $2.6 \mathrm{~L} / \mathrm{min} / \mathrm{m}^{2}$, and mean arterial pressure was maintained between 60 and $80 \mathrm{~mm} \mathrm{Hg}$. Intraoperative protection of the heart was performed using intermittent anteretrograde warm blood cardioplegia. Antegrade cardioplegia was performed through the cannula positioned in the aortic root. Left ventricular venting was accomplished in all patients through the right superior pulmonary vein. The coronary sinus was cannulated with a self-inflating cannula for retrograde cardioplegia delivery. The ascending aorta was cross-clamped above the origin of the coronary arteries, followed by the ante-retrograde cardioplegia using a blood-based cardioplegia solution containing $20 \mathrm{mmol} / \mathrm{L}$ of potassium chloride. Oxygenated blood for cardioplegia was taken via the special outlet port of the oxygenator and delivered into the aortic cannula or coronary sinus using peristaltic pump. Before entering the vessels, the blood was supplemented with $10 \%$ solution of potassium chloride $(\mathrm{KCl})$ via $\mathrm{T}$-connector using the syringe pump. The volume flow rate of blood-based cardioplegia was kept at $200 \mathrm{ml} / \mathrm{min}$ during both induction of cardioplegia and maintenance of cardioplegic arrest (Table 1). The first 
Table 1 Protocol of intermittent ante-retrograde warm blood cardioplegia

\begin{tabular}{llll}
\hline $\begin{array}{l}\text { Episode of cardioplegia } \\
\text { (No) and mode of infusion }\end{array}$ & $\begin{array}{l}\text { Volume flow rate of } \\
\text { blood delivery }(\mathbf{m l} / \mathbf{m i n})\end{array}$ & $\begin{array}{l}\text { Volume flow rate of delivery } \\
\text { of } \mathbf{1 0} \% \mathbf{~ K C l} \text { solution }(\mathbf{m l} / \mathbf{h})\end{array}$ & $\begin{array}{l}\text { Duration of cardioplegia } \\
\text { infusion (min) }\end{array}$ \\
\hline 1 - antegrade* & 200 & 100 (preceded by bolus dose of $4 \mathrm{ml})$ & 2.5 \\
1 - retrograde & 200 & 10 & 3.0 \\
2 - retrograde & 200 & 10 (preceded by bolus dose of $2 \mathrm{ml})$ & 3.0 \\
3 - retrograde & 200 & 10 & 3.0 \\
$4-$ retrograde & 200 & 10 & 4.0 \\
5 - retrograde & 200 & 10 & 5.0 \\
\hline
\end{tabular}

*first episode of cardioplegia consisted of 2.5-min antegrade infusion plus 3.0-min retrograde infusion.

episode of cardioplegia consisted of 2.5-min period of antegrade heart perfusion followed by $3.0-$ min period of retrograde perfusion. The beginning of antegrade delivery of blood was accompanied by bolus injection of $4 \mathrm{ml} \mathrm{10 \%}$ $\mathrm{KCl}$ in the cardioplegia line followed by its infusion at a rate of $100 \mathrm{ml} / \mathrm{h}$. During retrograde delivery of blood, the rate of $\mathrm{KCl}$ solution infusion was $10 \mathrm{ml} / \mathrm{h}$. The blood cardioplegia solution containing $8 \mathrm{mmol} / \mathrm{L}$ of potassium chloride was infused for maintenance of cardiac arrest with an interval of approximately $15 \mathrm{~min}$. The decrease in potassium concentration in the final cardioplegic solution was partially compensated by longer durations of subsequent $\left(4^{\text {th }}\right.$ and $\left.5^{\text {th }}\right)$ episodes of cardioplegia (Table 1$)$. The rationale for decreasing potassium concentration was to avoid hyperkalemia-induced myocardial injury and accelerate recovery of myocardial contractility during reperfusion.

The pressure in the coronary sinus was monitored throughout the procedure and was kept below $60 \mathrm{~mm}$ $\mathrm{Hg}$. During antegrade cardioplegia, the pressure in the ascending aorta was monitored by the manometer and manual inspection of the aorta was performed to verify aortic valve closure.

Infusion of vasopressor (mesatone) was used in the patients with systemic vascular resistance of less than 800 dynes $/ \mathrm{s} / \mathrm{cm}^{5}$. Epinephrine, norepinephrine, and dopamine were used for inotropic support. Patients received inotropes either based on the observation of reduced cardiac contractility during and after weaning from $\mathrm{CPB}$ (by direct visual inspection of the right ventricle and/or transesophageal echocardiography) or after measuring a reduced $\mathrm{CI}$ $\left(<2.0 \mathrm{~L} / \mathrm{min} / \mathrm{m}^{2}\right)$, or both.

\section{Preconditioning protocol}

All patients were randomized into one of the following 3 groups: (1) Control $(\mathrm{n}=30)$; (2) Perfusion $(\mathrm{n}=30)$; and (3) IP $(n=30)$. Randomization was performed in the surgery room; a sealed, nontransparent protocol envelope was opened for each patient and the patient was accordingly assigned to a group. The Control group included patients undergoing conventional CABG surgery. In the Perfusion group, a 12-min period of $\mathrm{CPB}$ was instituted before the application of the aortic cross-clamp in order to account for the effect of additional $\mathrm{CPB}$ time required for IP induction on the outcomes. In the IP group, preconditioning was elicited by cross-clamping the aorta and leaving the hemodynamically unloaded heart in the ischemic state for $3 \mathrm{~min}$. During preconditioning ischemia, the left vent was run at $50 \mathrm{ml} / \mathrm{min}$. A 3-min episode of ischemia was followed by $3 \mathrm{~min}$ of reperfusion with normokalemic blood delivered in the aortic root at a rate of $300 \mathrm{ml} / \mathrm{min}$. The second episode of $3 \mathrm{~min}$ of ischemia was initiated by the cessation of re(perfusion) through the antegrade cardioplegia cannula. The full IP protocol included 2 cycles of $3 \mathrm{~min}$ of ischemia plus $3 \mathrm{~min}$ of reperfusion. The second 3-min episode of reperfusion was followed by the initiation of standard ante-retrograde blood cardioplegia.

\section{Measurements}

The primary endpoint of the study was postoperative cTnI release. Blood samples for cTnI determination were obtained from each patient before the institution of $\mathrm{CPB}$ as well as 2, 6, 12, 24, and $48 \mathrm{~h}$ after surgery. Additional blood sampling was performed 7 days after surgery. BNP levels were determined preoperatively as well as on the 1st and 7th postoperative day. Serum levels of cTnI and BNP were measured using a chemiluminescent immunoassay (Architect i2000SR, Abbott Diagnostics, USA).

Left ventricular ejection fraction, left ventricular endsystolic volume, left ventricular end-diastolic volume, and left ventricular end-systolic and end-diastolic diameters were measured using echocardiography before surgery and on the 7th postoperative day. The cardiac index (CI) was calculated using the following formula: $\mathrm{CI}=$ cardiac output $(\mathrm{l} / \mathrm{min}) /$ body surface area $\left(\mathrm{m}^{2}\right)$. CI was calculated in all patients at 5 time points: (1) baseline (before induction of anesthesia); (2) prior to CPB; (3) after weaning from CPB; (4) $12 \mathrm{~h}$ after surgery; and (5) $24 \mathrm{~h}$ after surgery.

The duration of mechanical ventilation and length of stay in the ICU were recorded. The number of patients requiring inotropic support with $\geq 2$ agents, mean number of inotropic drugs used, and mean total duration of inotrope use (h) were also recorded. The physicians in 
ICU and Echo lab were blinded to the group assignments. Postoperative morbidity and mortality on day 20 after the operation were recorded.

\section{Statistical analysis}

Statistical analysis was performed using the SPSS 12.0 software package. All data in the text are expressed as mean \pm standard deviation (SD). The sample size per group was determined using the following parameters: $\mathrm{SD}$ values calculated on the basis of previous studies, desired confidence level (95\%), and acceptable difference in outcome between the groups (Statistics Calculator). The Kruskal-Wallis test was used to determine differences in the parameters analysed, followed by pairwise inter-group comparisons at each time point performed using non-parametric Mann-Whitney $U$ tests. Fisher's exact test was used to determine whether there were any differences between the groups in the number of patients requiring inotropic support with $\geq 2$ agents. $P$ values of $\leq 0.05$ were considered significant.

\section{Results}

\section{Perioperative characteristics of the patients}

The preoperative data of the patients were similar between the 3 groups. There were no significant differences in age, sex, New York Heart Association class, previous myocardial infarction, and comorbidities such as peripheral vascular disease and chronic obstructive pulmonary disease among the groups. The CPB time, aortic cross-clamping time, total duration of cardioplegia infusion, number of distal anastomoses and duration of mechanical ventilation were also similar among the groups (Table 2).

\section{cTnl and BNP levels}

According to the manufacturer's recommendations, the 99th percentile reference cutoff for the cTnI level was $0.3 \mathrm{ng} / \mathrm{mL}$. Prior to surgery, cTnI levels were well below the upper reference limit in all groups (Table 3). The maximum release of cTnI was observed between 6 and $24 \mathrm{~h}$ after surgery, followed by a progressive decrease in concentration. There were no differences in cTnI levels between the groups except for the cTnI level at the 7th postoperative day, which was significantly lower in the IP group than in the Perfusion group $(P<0.05$, Table 3$)$. The pre- and postoperative serum BNP levels are presented in Table 4. Although surgery resulted in significant elevation of BNP concentration, the BNP levels did not differ between the groups at any time point.

\section{Left ventricular function}

The pre- and postoperative echocardiographic parameters of left ventricular function did not differ among the groups (Table 5). The preoperative values of $\mathrm{CI}$ also did not differ among groups (Table 6). CI tended to decrease
Table 2 erioperative characteristics of the patients

\begin{tabular}{|c|c|c|c|}
\hline Characteristic & $\begin{array}{l}\text { Control } \\
(\mathrm{n}=30)\end{array}$ & $\begin{array}{l}\text { Perfusion } \\
(\mathrm{n}=30)\end{array}$ & $\begin{array}{l}\text { IP } \\
(n=30)\end{array}$ \\
\hline Age (years) & $55.4 \pm 5.2$ & $57.3 \pm 5.6$ & $56.6 \pm 4.3$ \\
\hline Gender (male/female) & $5 / 25$ & $3 / 27$ & $4 / 26$ \\
\hline Previous myocardial infarction & $18(60 \%)$ & $20(67 \%)$ & $18(60 \%)$ \\
\hline NYHA class II & $21(70 \%)$ & $22(73 \%)$ & $23(77 \%)$ \\
\hline NYHA class III & $9(30 \%)$ & $8(27 \%)$ & $7(23 \%)$ \\
\hline COPD & $11(36 \%)$ & $10(33 \%)$ & $9(30 \%)$ \\
\hline PAD & $5(17 \%)$ & $6(20 \%)$ & $5(17 \%)$ \\
\hline CPB time (min) & $86 \pm 28$ & $98 \pm 29$ & $89 \pm 32$ \\
\hline $\begin{array}{l}\text { Aortic cross-clamping } \\
\text { time (min) }\end{array}$ & $48 \pm 16$ & $49 \pm 19$ & $52 \pm 23$ \\
\hline $\begin{array}{l}\text { Total duration of } \\
\text { cardioplegia (min) }\end{array}$ & $9.8 \pm 2.5$ & $9.8 \pm 3.2$ & $9.9 \pm 3.6$ \\
\hline Number of distal anastomoses & $3.2 \pm 0.8$ & $3.2 \pm 0.5$ & $3.4 \pm 0.7$ \\
\hline $\begin{array}{l}\text { Graft material (LIMA/saphenous } \\
\text { vein/radial artery) (\%) }\end{array}$ & 100/100/13.3 & 100/100/13.3 & 100/100/16.7 \\
\hline $\begin{array}{l}\text { Duration of mechanical } \\
\text { ventilation (h) }\end{array}$ & $14 \pm 6$ & $14 \pm 4$ & $12 \pm 3$ \\
\hline
\end{tabular}

after induction of anesthesia and increased after weaning from CPB. Immediately after weaning from $\mathrm{CPB}$, the $\mathrm{CI}$ was significantly higher in the IP group compared with the Control and Perfusion groups $(P<0.01$, Table 6). At 12 and $24 \mathrm{~h}$ after surgery, the CI was lower in the Perfusion group than in the Control group $(P<0.05)$. IP resulted in a significantly higher $\mathrm{CI}$ at $24 \mathrm{~h}$ after surgery compared with that in the Perfusion group $(P<0.05)$.

\section{Postoperative course and inotrope requirement}

None of the patients experienced perioperative myocardial infarction or stroke. No complications of the procedure were recorded in the IP group. There was 1 case of resternotomy in the Perfusion group because of persistent

Table 3 Pre- and postoperative serum levels of cardiac troponin I (ng/ml)

\begin{tabular}{llll}
\hline Time point & $\begin{array}{l}\text { Control } \\
(\mathbf{n}=\mathbf{3 0})\end{array}$ & $\begin{array}{l}\text { Perfusion } \\
(\mathbf{n}=\mathbf{3 0})\end{array}$ & IP $(\mathbf{n}=\mathbf{3 0})$ \\
\hline Before surgery & $0.004 \pm 0.008$ & $0.005 \pm 0.011$ & $0.010 \pm 0.012$ \\
2 h after surgery & $0.84 \pm 0.79$ & $1.61 \pm 1.68$ & $1.18 \pm 0.77$ \\
6 h after surgery & $1.48 \pm 0.83$ & $1.57 \pm 0.78$ & $1.65 \pm 0.98$ \\
12 h after surgery & $1.52 \pm 0.62$ & $1.57 \pm 0.89$ & $1.56 \pm 0.61$ \\
24 h after surgery & $1.67 \pm 1.03$ & $1.92 \pm 2.45$ & $1.17 \pm 0.56^{*}$ \\
48 h after surgery & $0.97 \pm 0.61$ & $1.32 \pm 1.83$ & $0.75 \pm 0.42$ \\
7 days after surgery & $0.19 \pm 0.23$ & $0.33 \pm 0.88$ & $0.10 \pm 0.05^{*}$ \\
\hline
\end{tabular}

Data are mean \pm standard deviation. IP - local ischemic preconditioning. ${ }^{*} P<0.05$ versus Perfusion. 
Table 4 Pre- and postoperative serum levels of brain natriuretic peptide $(\mathrm{ng} / \mathrm{ml})$

\begin{tabular}{llll}
\hline Time point & $\begin{array}{l}\text { Control } \\
(\mathbf{n}=\mathbf{3 0})\end{array}$ & $\begin{array}{l}\text { Perfusion } \\
(\mathbf{n}=\mathbf{3 0})\end{array}$ & IP $(\mathbf{n}=\mathbf{3 0})$ \\
\hline Before surgery & $41.6 \pm 25.5$ & $33.7 \pm 25.1$ & $43.8 \pm 40.1$ \\
24 h after surgery & $268.2 \pm 129.2$ & $310.2 \pm 210.3$ & $267.0 \pm 200.3$ \\
7 days after surgery & $147.5 \pm 59.5$ & $171.0 \pm 98.2$ & $160.0 \pm 82.6$ \\
\hline Data are mean + standard deviation. IP - local ischemic preconditioning.
\end{tabular}

bleeding. Most of the patients were transferred from the ICU to the regular ward on the 1st postoperative day. There were 5,7 , and 2 patients who were transferred from the ICU on the 2nd day after surgery in the Control, Perfusion, and IP groups, respectively. One patient in the Control group and 1 patient in the Perfusion group were transferred from the ICU on the 3rd postoperative day. The reasons for prolonged postoperative stay in the ICU were heart failure, respiratory failure, and encephalopathy. The number of patients requiring inotropic support with $\geq 2$ agents after surgery was significantly lower in the IP and Perfusion group than in the Control group $(P<0.05$, Table 7$)$. The mean number of inotropic drugs used per patient, as well as the mean total duration of inotrope use and inotrope doses, were similar in all the groups (Table 7).

\section{Discussion}

Despite significant progress in the development of intraoperative myocardial protection techniques, including both optimization of cardioplegia regimens and implementation of new cardioplegia solutions [18,19], high-

Table 5 Pre- and postoperative echocardiographic parameters of left ventricular function

\begin{tabular}{|c|c|c|c|}
\hline Time point & Control $(n=30)$ & Perfusion $(n=30)$ & IP $(n=30)$ \\
\hline \multicolumn{4}{|c|}{ Left ventricular ejection fraction, $\%$} \\
\hline Before surgery & $63.7 \pm 6.2$ & $63.6 \pm 6.3$ & $61.6 \pm 5.9$ \\
\hline 7 days after surgery & $63.0 \pm 6.6$ & $61.9 \pm 7.0$ & $62.5 \pm 6.7$ \\
\hline \multicolumn{4}{|c|}{ Left ventricular end-systolic volume, mL } \\
\hline Before surgery & $50.4 \pm 15.1$ & $49.7 \pm 15.1$ & $53.3 \pm 14.8$ \\
\hline 7 days after surgery & $48.2 \pm 11.9$ & $50.8 \pm 15.3$ & $50.5 \pm 14.2$ \\
\hline \multicolumn{4}{|c|}{ Left ventricular end-diastolic volume, mL } \\
\hline Before surgery & $137.3 \pm 21.9$ & $134.6 \pm 22.1$ & $137.1 \pm 18.7$ \\
\hline 7 days after surgery & $130.1 \pm 13.7$ & $130.9 \pm 22.5$ & $134.0 \pm 19.7$ \\
\hline \multicolumn{4}{|c|}{ Left ventricular end-systolic diameter, mm } \\
\hline Before surgery & $35.4 \pm 4.2$ & $34.5 \pm 4.5$ & $34.2 \pm 3.7$ \\
\hline 7 days after surgery & $33.6 \pm 3.3$ & $34.8 \pm 4.1$ & $34.3 \pm 3.6$ \\
\hline \multicolumn{4}{|c|}{ Left ventricular end-diastolic diameter, mm } \\
\hline Before surgery & $53.0 \pm 3.0$ & $52.7 \pm 3.7$ & $53.2 \pm 3.7$ \\
\hline 7 days after surgery & $51.9 \pm 2.2$ & $52.4 \pm 3.8$ & $52.6 \pm 3.2$ \\
\hline
\end{tabular}

Data are mean \pm standard deviation. IP - local ischemic preconditioning.
Table 6 Pre- and postoperative values of cardiac index $\left(\mathrm{L} / \mathrm{min} / \mathrm{m}^{2}\right)$

\begin{tabular}{llll}
\hline Time point & $\begin{array}{l}\text { Control } \\
(\mathbf{n}=\mathbf{3 0})\end{array}$ & $\begin{array}{l}\text { Perfusion } \\
(\mathbf{n}=\mathbf{3 0})\end{array}$ & IP $(\mathbf{n}=\mathbf{3 0})$ \\
\hline Before anesthesia & $2.7 \pm 0.4$ & $2.6 \pm 0.4$ & $2.7 \pm 0.3$ \\
Prior to CPB & $1.9 \pm 0.2$ & $2,0 \pm 0.4$ & $1.9 \pm 0.2$ \\
After weaning from CPB & $3.0 \pm 0.2$ & $2.9 \pm 0.3$ & $3.4 \pm 0.3^{* * *}$ \\
$12 \mathrm{~h}$ after surgery & $3.1 \pm 0.7$ & $2.8 \pm 0.4^{*}$ & $2.9 \pm 0.6$ \\
24 $\mathrm{h}$ after surgery & $3.0 \pm 0.5$ & $2.7 \pm 0.3^{*}$ & $2.9 \pm 0.3 \&$
\end{tabular}

Data are mean \pm standard deviation. CPB - cardiopulmonary bypass; IP - local ischemic preconditioning. ${ }^{*} P<0.05$ versus Control; ${ }^{* *} P<0.01$ vs. Control; ${ }^{\#} P<0.01$ vs. Perfusion; $\&-P<0.05$ vs. Perfusion.

risk patients may develop severe myocardial IRI resulting in low cardiac output syndrome, left ventricular stunning, life-threatening ventricular arrhythmias, and perioperative myocardial infarction [20-22]. Considering the results of the numerous experimental studies, IP could be useful in reducing these manifestations of cardiac IRI. The first encouraging data on the effectiveness of IP in the settings of cardiac surgery were obtained by Yellon et al. [23] in 1993, who showed that 2 cycles of $3 \mathrm{~min}$ of global ischemia and 2 min of reperfusion prior to a 10-min episode of cross-clamp fibrillation without cardioplegia resulted in better preservation of tissue ATP compared with controls. Two subsequent studies by the same group have demonstrated that a similar IP protocol reduces postoperative cardiac troponin T (cTnT) levels [10,24]. An IP-mediated reduction in postoperative creatine kinase $\mathrm{MB}$ (CK-MB) levels has been found after antegrade cold crystalloid [25] and blood $[14,26]$ cardioplegia. The infarct-limiting effect of IP was also verified by a significantly decreased cTnT and $\mathrm{cTnI}$ release in the patients undergoing open heart surgery with cardioplegia $[27,28]$. In addition, IP has been found to improve several important clinical parameters, including the incidence of arrhythmia [14,26,29], duration of artificial ventilation [28], and inotrope use [11,14,26]. Another group of endpoints for myocardial protection comprises left and right ventricular hemodynamic parameters. Improved left ventricular contractility during the postoperative period due to IP application has been found in several studies $[11,25]$. It has been also shown that IP can improve not only the left ventricular function, but also the right ventricular ejection fraction [13].

According to the results of systematic review of Heusch [30], 50\% (8 out of 16) of IP studies in cardiac surgery demonstrated a significant reduction in infarct size, whereas the remaining studies reported either a neutral or even negative outcome. Taking into account the lack of significant infarct size limitation due to IP in the present study, it seems to be important to analyze the subset of IP studies failing to show a reduction in myocardial injury. A significant increase in the level of CK-MB was observed after the application of 2 cycles of $3 \mathrm{~min}$ of ischemia and $2 \mathrm{~min}$ of reperfusion prior 
to the onset of continuous retrograde warm cardioplegia [31]. The negative result of this study might be well attributed to the lack of test (prolonged) myocardial ischemia, whereas the increased level of CK-MB in the IP group reflects the sublethal myocardial injury caused by the preconditioning procedure itself. Kaukoranta et al. [32] noted a trend toward increased levels of CK-MB and cTnT after IP-an observation that could also be explained by the insufficient severity of test ischemia since this study utilized an almost uninterrupted coronary infusion of cardioplegia. The duration of myocardial ischemia was only $9 \%$ and $8 \%$ of the total cross-clamp time in IP and control groups, respectively. It should be noted, however, that IP failed to limit infarct size in several studies utilizing intermittent cold blood cardioplegia associated with an appreciable duration of test ischemia [33,34]. Nonetheless, these data led to the major conclusion that the limitation of significant infarct size through IP is more likely to be obtained in high-risk patients with the longest aortic cross-clamp times and severe left ventricular hypertrophy [35]. These patients are more likely to sustain significant perioperative myocardial injury during surgery, which might be potentially attenuated by protective maneuvers such as IP. Clinical data also indicate that IP may be especially useful for the preservation of right ventricular function because the right ventricle may be suboptimally protected during ante-retrograde cardioplegia [13].

The protocol for IP is crucial for effective myocardial protection. Experimental studies have indicated that the infarct-limiting effect of IP is generally proportional to the number of brief preconditioning stimuli, whereas the application of a single IP episode results in a marginal protective effect [36]. In this regard, the lack of IP effect on myocardial infarct size in some clinical trials could be, at least in part, attributed to the application of a single preconditioning episode instead of repeated episodes $[11,32,37]$. To our knowledge, none of the clinical studies on IP effects in cardiac surgery used an IP protocol consisting of $>2$ episodes of brief ischemia-reperfusion. The likely explanation for this fact is that repetitive aortic cross-clamping and subsequent declamping significantly increases the risk of atheroembolism. It is known that even the standard procedure of aortic cross-clamping in the patients with advanced atherosclerosis of the ascending aorta is associated with microembolism of the brain vessels, resulting in a varying degree of neurocognitive impairment $[38,39]$. Therefore, it is not surprising that the increased risk of atheroembolism due to repetitive aortic cross-clamping is one of the major factors hindering the routine application of IP in cardiac surgery [17]. Of note, the results of meta-analysis including 22 clinical trials on IP in cardiac surgery (933 patients), showed that IP significantly reduced the incidence of arrhythmias, postoperative inotrope use, and duration of ICU stay, which was corroborated by the results of the present study [40]. The authors speculated that the most rigorous evidence for the protective effect of IP could be obtained if one could demonstrate a twofold decrease in mortality, which, however, would require an inclusion of $\geq 3800$ patients in each arm of the study. The introduction of IP protocols based on the no-touch-to-aorta techniques may facilitate this task.

A further protocol-related factor that plays an important role in the expression of IP-mediated protective phenotype is the ratio between the duration of ischemic and reperfusion phase of preconditioning cycle. Experimental data clearly demonstrate that IP is most effective when the duration of the reperfusion episode is equal to that of the ischemic episode or exceeds it. The indirect evidence supporting the validity of this notion was derived from the results of a recent clinical trial on IP that showed no infarct size limitation after the application of 2 cycles of 2 min of ischemia and $1 \mathrm{~min}$ of reperfusion [41].

Several studies have tested the hypothesis that CBP itself may elicit a preconditioning-like response, primarily through the development of a low-grade systemic inflammatory response [42]. Important data supporting this concept were obtained by Ghosh and Galinanes [37], who found a significant cardioprotective effect of IP only in patients undergoing off-pump CABG and not in those subjected to cardioplegia or intermittent cross-clamp fibrillation. Subsequently, IP has been shown to exert a significant protective effect in other studies performed on CABG patients operated off-pump [43,44]. However, it seems that the preconditioning-like effect of CPB may still permit additional protection afforded by IP. This idea is supported by the large body of evidence demonstrating IP-

Table 7 Parameters of postoperative inotrope requirements

\begin{tabular}{llll}
\hline Parameter & Control $(\mathbf{n}=\mathbf{3 0})$ & Perfusion $(\mathbf{n}=\mathbf{3 0})$ & IP $(\mathbf{n}=\mathbf{3 0})$ \\
\hline No of patients treated with $\geq 2$ agents & 8 & $5^{*}$ & $4^{*}$ \\
Mean number of inotropic drugs & $0.7 \pm 0.8$ & $0.5 \pm 0.7$ & $0.5 \pm 0.7$ \\
Mean total duration of inotrope use $(\mathrm{h})$ & $8.8 \pm 12.1$ & $7.6 \pm 13.4$ & $6.6 \pm 8.9$ \\
Mean dose of epinephrine $(\mu \mathrm{g} / \mathrm{kg} / \mathrm{min})$ & $0.014 \pm 0.022$ & $0.010 \pm 0.019$ & $0.008 \pm 0.017$ \\
Mean dose of norepinephrine $(\mu \mathrm{g} / \mathrm{kg} / \mathrm{min})$ & $0.035 \pm 0.025$ & $0.028 \pm 0.036$ & $0.051 \pm 0.045$ \\
Mean dose of dopamine $(\mu \mathrm{g} / \mathrm{kg} / \mathrm{min})$ & $0.75 \pm 1.57$ & $0.35 \pm 1.14$ & $0.89 \pm 1.83$ \\
\hline
\end{tabular}

Data are mean \pm standard deviation. CPB - cardiopulmonary bypass; IP - local ischemic preconditioning. ${ }^{*} P<0.05$ versus Control. 
induced limitation of infarct size and amelioration of clinical parameters in the patients undergoing CBP $[30,40]$.

Although BNP measurements are not routinely used in the studies on myocardial protection, the data start to accumulate that BNP measurement might be also relevant for patients undergoing cardiac surgery. It is well established that BNP levels are severely increased after heart transplantation (e.g., [45]) including the patients without severe hemodynamic perturbations or allograft rejection. Postoperative plasma BNP is independent predictor of cardiac dysfunction after cardiac surgery [46]. Therefore, we were interested to see whether BNP can be used as a secondary biochemical marker of myocardial protection. Although we noted significant elevation of BNP at $24 \mathrm{~h}$ postoperatively in all groups, there were no inter-group differences.

In conclusion, the present study describes a new technique of IP induction in cardiac surgery patients. This technique does not require repetitive aortic cross-clamping, which makes the preconditioning procedure safe for the patients with advanced atherosclerosis. The application of this technique of IP was associated with certain benefits, including improved left ventricular function after weaning from $\mathrm{CPB}$ and a reduced need for inotropic support. However, the infarct-limiting effect of IP in the early postoperative period was not evident-this requires additional refinement of the IP protocol as well as the identification of patient categories that may benefit from the application of IP.

\section{Conclusions}

The IP procedure described can be performed safely in cardiac surgery patients. The application of this technique of IP was associated with certain benefits, including improved left ventricular function after weaning from $\mathrm{CPB}$ and a reduced need for inotropic support. However, the infarct-limiting effect of IP in the early postoperative period was not evident. The procedure does not involve repetitive aortic cross-clamping, thus avoiding possible embolic complications.

\section{Abbreviations}

BNP: Brain natriuretic peptide; Cl: Cardiac index; CPB: Cardiopulmonary bypass; CABG: Coronary artery bypass graft; CAD: Coronary artery disease; CK-MB: Creatine kinase MB; ICU: Intensive care unit; IRI: Ischemia-reperfusion injury; IP: Ischemic preconitioning; Tnl: Troponin I.

\section{Competing interests}

The authors declare that they have no competing interests.

\section{Authors' contributions}

DIK, VOK, and VKG performed surgery, analyzed and interpreted the data, performed the statistical analysis, and wrote the manuscript; TAS and WD performed biochemical and functional measurements, analyzed and interpreted the data, performed the statistical analysis; MMG and EVS contributed to the design the study, helped to draft the final manuscript and added important comments to the paper. All authors read and approved the final manuscript.

\section{Acknowledgments}

This work was supported by the grant of the President of the Russian Federation for support of leading scientific groups 1611.2014.7 (to DIK and MMG).

\section{Author details}

${ }^{1}$ Institute of Experimental Medicine, Federal Almazov Medical Research Centre, Saint Petersburg, Russian Federation. ${ }^{2}$ Institute of Heart and Vessels, Federal Almazov Medical Research Centre, Saint Petersburg, Russian Federation. ${ }^{3}$ Department of Pathophysiology, First I.P. Pavlov Federal Medical University of St. Petersburg, Saint Petersburg, Russian Federation.

Received: 1 September 2014 Accepted: 7 January 2015

Published online: 22 January 2015

\section{References}

1. Johnson WM, Smith JM, Woods SE, Hendy MP, Hiratzka LF. Cardiac surgery in octogenarians: does age alone influence outcomes? Arch Surg. 2005;140:1089-93.

2. Salazar E, Torres J, Barragan R, Lopez M, Lasses LA. Aortic valve replacement in patients 70 years and older. Clin Cardiol. 2004;27:565-70.

3. Hakala T, Pitkanen O, Halonen P, Mustonen J, Turpeinen A, Hippelainen M. Early and late outcome after coronary artery bypass surgery in diabetic patients. Scand Cardiovasc J. 2005;39:177-81.

4. Sommerhaug RG, Wolfe SF, Reid DA, Lindsey DE, Prato SJ, Frounfelkner LE, et al. Comparative use of cold blood potassium cardioplegia in coronary bypass patients necessitating long (2.5-6 h) versus short (less than $1.5 \mathrm{~h}$ ) aortic cross-clamp times. Clin Cardiol. 1988;11:690-5.

5. Mariani J, Ou R, Bailey M, Rowland M, Nagley P, Rosenfeldt F, et al. Tolerance to ischemia and hypoxia is reduced in aged human myocardium. J Thorac Cardiovasc Surg. 2000;120:660-7.

6. Alegria JR, Miller TD, Gibbons RJ, Yi QL, Yusuf S, Collaborative Organization of RheothRx Evaluation (CORE) Trial Investigators. Infarct size, ejection fraction, and mortality in diabetic patients with acute myocardial infarction treated with thrombolytic therapy. Am Heart J. 2007;154:743-50.

7. Murry $C E$, Jennings $R B$, Reimer KA. Preconditioning with ischemia: a delay of lethal cell injury in ischemic myocardium. Circulation. 1986;74:1124-36.

8. Yellon DM, Downey JM. Preconditioning the myocardium: from cellular physiology to clinical cardiology. Physiol Rev. 2003;83:1113-51.

9. Galagudza MM, Blokhin IO, Shmonin AA, Mischenko KA. Reduction of myocardial ischemia-reperfusion injury with pre- and postconditioning: molecular mechanisms and therapeutic targets. Cardiovasc Hematol Disord Drug Targets. 2008;8:47-65.

10. Jenkins DP, Pugsley WB, Alkhulaifi AM, Kemp M, Hooper J, Yellon DM. Ischaemic preconditioning reduces troponin T release in patients undergoing coronary artery bypass surgery. Heart. 1997;77:314-8.

11. Wu ZK, Tarkka M, Pehkonen E, Kaukinen L, Honkonen EL, Kaukinen S. Ischaemic preconditioning has beneficial effects on left ventricular haemodynamic function after a coronary artery bypass grafting operation. Scand Cardiovasc J. 2000;34:247-53.

12. Wu ZK, Tarkka M, Pehkonen E, Kaukinen L, Honkonen EL, Kaukinen S. Beneficial effects of ischemic preconditioning on right ventricular function after coronary artery bypass grafting. Ann Thorac Surg. 2000;70:1551-7.

13. Wu ZK, livainen T, Pehkonen E, Laurikka J, Tarkka MR. Antiarrhythmic effect of ischemic preconditioning in recent unstable angina patients undergoing coronary artery bypass grafting. World I Surg. 2004;28:74-9.

14. Illes RW, Swoyer KD. Prospective, randomized clinical study of ischemic preconditioning as an adjunct to intermittent cold blood cardioplegia. Ann Thorac Surg. 1998;65:748-52.

15. Li G, Chen S, Lu E, Li Y. Ischemic preconditioning improves preservation with cold blood cardioplegia in valve replacement patients. Eur J Cardiothorac Surg. 1999;15:653-7.

16. Luo WJ. Ischemic preconditioning in children undergoing open heart operation. Ann Thorac Surg. 1998;66:2163-4.

17. Valen G, Vaage J. Pre- and postconditioning during cardiac surgery. Basic Res Cardiol. 2005;100:179-86.

18. Maruyama Y, Chambers DJ. Myocardial protection: efficacy of a novel magnesium-based cardioplegia (RS-C) compared to St Thomas' Hospital cardioplegic solution. Interact Cardiovasc Thorac Surg. 2008;7:745-9.

19. Minasian SM, Galagudza MM, Dmitriev YV, Kurapeev DI, Vlasov TD. Myocardial protection against global ischemia with Krebs-Henseleit buffer-based cardioplegic solution. J Cardiothorac Surg. 2013;8:60. 
20. Dahlin LG, Olin C, Svedjeholm R. Perioperative myocardial infarction in cardiac surgery-risk factors and consequences: a case control study. Scand Cardiovasc J. 2000;34:522-7.

21. Masse L, Antonacci M. Low cardiac output syndrome: identification and management. Crit Care Nurs Clin North Am. 2005;17:375-83.

22. Westaby S, Balacumaraswami L, Sayeed R. Maximizing survival potential in very high risk cardiac surgery. Heart Fail Clin. 2007;3:159-80.

23. Yellon DM, Alkhulaifi AM, Pugsley WB. Preconditioning the human myocardium. Lancet. 1993;342:276-7.

24. Teoh LK, Grant R, Hulf JA, Pugsley WB, Yellon DM. A comparison between ischemic preconditioning, intermittent cross-clamp fibrillation and cold crystalloid cardioplegia for myocardial protection during coronary artery bypass graft surgery. Cardiovasc Surg. 2002;10:251-5.

25. Lu EX, Chen SX, Yuan MD, Hu TH, Zhou HC, Luo WJ, et al. Preconditioning improves myocardial preservation in patients undergoing open heart operations. Ann Thorac Surg. 1997;64:1320-4.

26. Buyukates M, Kalaycioglu S, Oz E, Soncul H. Effects of ischemic preconditioning in human heart. J Card Surg. 2005;20:241-5.

27. Szmagala P, Morawski W, Krejca M, Gburek T, Bochenek A. Evaluation of perioperative myocardial tissue damage in ischemically preconditioned human heart during aorto coronary bypass surgery. J Cardiovasc Surg (Torino). 1998;39:791-5

28. Ji B, Liu M, Liu J, Wang G, Feng W, Lu F, et al. Evaluation by cardiac troponin I: the effect of ischemic preconditioning as an adjunct to intermittent blood cardioplegia on coronary artery bypass grafting. Card Surg. 2007;22:394-400.

29. Wu ZK, livainen T, Pehkonen E, Laurikka J, Tarkka MR. Ischemic preconditioning suppresses ventricular tachyarrhythmias after myocardial revascularization. Circulation. 2002;106:3091-6.

30. Heusch G. Cardioprotection: chances and challenges of its translation to the clinic. Lancet. 2013;381:166-75.

31. Perrault LP, Menasche P, Bel A, De Chaumaray T, Peynet J, Mondry A, et al. Ischemic preconditioning in cardiac surgery: a word of caution. J Thorac Cardiovasc Surg. 1996:112:1378-86.

32. Kaukoranta PK, Lepojarvi MV, Kiviluoma KT, Ylitalo KV, Peuhkurinen KJ. Myocardial protection during antegrade versus retrograde cardioplegia. Ann Thorac Surg. 1998;66:755-61.

33. Cremer J, Steinhoff G, Karck M, Ahnsell T, Brandt M, Teebken OE, et al Ischemic preconditioning prior to myocardial protection with cold blood cardioplegia in coronary surgery. Eur J Cardiothorac Surg. 1997:12:753-8.

34. Wu ZK, Tarkka MR, Eloranta J, Pehkonen E, Kaukinen L, Honkonen EL, et al. Effect of ischemic preconditioning on myocardial protection in coronary artery bypass graft patients: can the free radicals act as a trigger for ischemic preconditioning? Chest. 2001;119:1061-8.

35. Hausenloy DJ, Baxter G, Bell R, Botker HE, Davidson SM, Downey J, et al. Translating novel strategies for cardioprotection: the Hatter Workshop Recommendations. Basic Res Cardiol. 2010;105:677-86.

36. Liu Y, Downey JM. Ischemic preconditioning protects against infarction in rat heart. Am J Physiol. 1992;263:H1107-12.

37. Ghosh S, Galinanes M. Protection of the human heart with ischemic preconditioning during cardiac surgery: role of cardiopulmonary bypass. J Thorac Cardiovasc Surg. 2003;126:133-42.

38. BhaskerRao B, VanHimbergen D, Edmonds Jr HL, Jaber S, Ali AT, Pagni S, et al. Evidence for improved cerebral function after minimally invasive bypass surgery. J Card Surg. 1998;13:27-31.

39. Reichenspurner $H$, Navia JA, Berry G, Robbins RC, Barbut D, Gold JP, et al. Particulate emboli capture by an intra-aortic filter device during cardiac surgery. J Thorac Cardiovasc Surg. 2000;119:233-41.

40. Walsh SR, Tang TY, Kullar P, Jenkins DP, Dutka DP, Gaunt ME. Ischaemic preconditioning during cardiac surgery: systematic review and meta-analysis of perioperative outcomes in randomised clinical trials. Eur J Cardiothorac Surg. 2008;34:985-94.

41. Jebeli M, Esmaili HR, Mandegar MH, Rasouli MR, Eghtesadi-Araghi P, Mohammadzadeh $\mathrm{R}$, et al. Evaluation of the effects of ischemic preconditioning with a short reperfusion phase on patients undergoing a coronary artery bypass graft. Ann Thorac Cardiovasc Surg. 2010;16:248-52.

42. Burns PG, Krukenkamp IB, Calderone CA, Gaudette GR, Bukhari EA, Levitsky S. Does cardiopulmonary bypass alone elicit myoprotective preconditioning? Circulation. 1995;92:11447-51.
43. Laurikka J, Wu ZK, lisalo P, Kaukinen L, Honkonen EL, Kaukinen S, et al. Regional ischemic preconditioning enhances myocardial performance in off-pump coronary artery bypass grafting. Chest. 2002;121:1183-99.

44. Wu ZK, livainen T, Pehkonen E, Laurikka J, Tarkka MR. Arrhythmias in off-pump coronary artery bypass grafting and the antiarrhythmic effect of regional ischemic preconditioning. J Cardiothorac Vasc Anesth. 2003;17:459-64.

45. Talha S, Charloux A, Enache I, Piquard F, Geny B. Mechanisms involved in increased plasma brain natriuretic peptide after heart transplantation. Cardiovasc Res. 2011;89:273-81.

46. Provenchère S, Berroeta C, Reynaud C, Baron G, Poirier I, Desmonts JM, et al Plasma brain natriuretic peptide and cardiac troponin I concentrations after adult cardiac surgery: association with postoperative cardiac dysfunction and 1-year mortality. Crit Care Med. 2006;34:995-1000.

\section{Submit your next manuscript to BioMed Central and take full advantage of:}

- Convenient online submission

- Thorough peer review

- No space constraints or color figure charges

- Immediate publication on acceptance

- Inclusion in PubMed, CAS, Scopus and Google Scholar

- Research which is freely available for redistribution 